\title{
Effects of smoking on the genetic risk of obesity: the population architecture using genomics and epidemiology study
}

Megan D Fesinmeyer ${ }^{1}$, Kari E North ${ }^{2,3}$, Unhee Lim ${ }^{4}$, Petra Bůžková ${ }^{5}$, Dana C Crawford ${ }^{6}$, Jeffrey Haessler ${ }^{1}$, Myron D Gross', Jay H Fowke ${ }^{8}$, Robert Goodloe ${ }^{6}$, Shelley-Ann Love', Misa Graff', Christopher S Carlson', Lewis H Kuller ${ }^{9}$, Tara C Matise ${ }^{10}$, Ching-Ping Hong ${ }^{11}$, Brian E Henderson ${ }^{12}$, Melissa Allen ${ }^{6}$, Rebecca R Rohde ${ }^{3}$, Ping Mayo ${ }^{6}$, Nathalie Schnetz-Boutaud ${ }^{6}$, Kristine R Monroe ${ }^{12}$, Marylyn D Ritchie ${ }^{6}$, Ross L Prentice ${ }^{1}$, Lawrence N Kolonel ${ }^{4}$, JoAnn E Manson ${ }^{13}$, James Pankow ${ }^{11}$, Lucia A Hindorff ${ }^{14}$, Nora Franceschini ${ }^{3}$, Lynne R Wilkens ${ }^{4}$, Christopher A Haiman ${ }^{12}$, Loic Le Marchand ${ }^{4}$ and Ulrike Peters ${ }^{1 *}$

\begin{abstract}
Background: Although smoking behavior is known to affect body mass index (BMI), the potential for smoking to influence genetic associations with BMl is largely unexplored.

Methods: As part of the 'Population Architecture using Genomics and Epidemiology (PAGE)' Consortium, we investigated interaction between genetic risk factors associated with BMI and smoking for 10 single nucleotide polymorphisms (SNPs) previously identified in genome-wide association studies. We included 6 studies with a total of 56,466 subjects (16,750 African Americans (AA) and 39,716 European Americans (EA)). We assessed effect modification by testing an interaction term for each SNP and smoking (current vs. former/never) in the linear regression and by stratified analyses.
\end{abstract}

Results: We did not observe strong evidence for interactions and only observed two interactions with $p$-values $<0.1$ : for rs6548238/TMEM18, the risk allele (C) was associated with BMI only among AA females who were former/never smokers ( $\beta=0.018, p=0.002$ ), vs. current smokers $(\beta=0.001, p=0.95$, pinteraction $=0.10$ ). For rs $9939609 / F T O$, the $A$ allele was more strongly associated with $\mathrm{BMl}$ among current smoker EA females $\left(\beta=0.017, p=3.5 \times 10^{-5}\right)$, vs. former/never smokers $(\beta=0.006, p=0.05$, pinteraction $=0.08)$.

Conclusions: These analyses provide limited evidence that smoking status may modify genetic effects of previously identified genetic risk factors for BMI. Larger studies are needed to follow up our results.

Clinical Trial Registration: NCT00000611

Keywords: Obesity, Body mass index, Genome-wide association study, Genetic risk factor, Smoking interactions, Genetic epidemiology

\footnotetext{
* Correspondence: upeters@fhcrc.org

${ }^{1}$ Division of Public Health Sciences, Fred Hutchinson Cancer Research Center,

1100 Fairview Ave N, M4-B402, PO Box 19024, Seattle, WA 98109-1024, USA

Full list of author information is available at the end of the article
} 


\section{Background}

The relationship between BMI and smoking is complex. Genetic variation is partially responsible for determining BMI, and genome-wide association studies (GWAS) have identified multiple variants associated with body mass index (BMI) in novel loci [1]. Lifestyle factors also play a key role in determining BMI: smoking affects body fat distribution [2], and current smokers tend to have lower BMI than non-smokers. The mechanism by which smoking regulates adiposity likely involves both appetite suppression via neural pathways [3] and interactions with energy-regulating hormonal feedback loops [4]. The interrelationship between BMI-setting genetic pathways and smoking behavior remains to be explored.

This study examines the potential for effect modification by smoking in the well-replicated association between GWAS-identified SNPs and BMI, using data derived from 56,466 European American (EA) and African American (AA) men and women as part of the NHGRI-supported 'Population Architecture using Genomics and Epidemiology (PAGE)' Consortium [5]. We hypothesize that genetic associations with BMI may differ by smoking status. Our results may lead to better understanding of the combined effects of genetics and smoking on obesity among $\mathrm{AA}$ and EA men and women.

\section{Methods}

\section{Study populations}

PAGE involves several studies, described in detail elsewhere [5]. PAGE studies included in this analysis are Atherosclerosis Risk in Communities Study (ARIC), Coronary Artery Risk in Young Adults (CARDIA), Cardiovascular Health Study (CHS), Women's Health Initiative (WHI), Multiethnic Cohort (MEC), and Epidemiologic Architecture for Genes Linked to Environment (EAGLE) accessing the National Health and Nutrition Examination Surveys (NHANES). All studies collected self-identified racial/ethnic group and baseline smoking status via questionnaire. All studies were approved by Institutional Review Boards at their respective sites, and all participants provided informed consent.

To reduce the likelihood of including individuals with extreme BMI due to a comorbid condition or a rare mutation, these analyses only included subjects with BMI $\geq 18.5$ and $<70$. In our prior analyses, we found that using tighter $\mathrm{BMI}$ restrictions (i.e., BMI $<40$ and $\mathrm{BMI}<50$ ) did not substantially alter results [6]. A total of 56,466 participants were selected from the PAGE consortium for analysis.

\section{Anthropometric measurements}

In MEC, self-reported height and weight were used to calculate baseline BMI (calculated as weight $(\mathrm{kg}) \div$ height $\left.(m)^{2}\right)$. Multiple studies have described systematic biases in self-reported compared to measured height and weight; yet in general these differences are small $(<1.0$ $\mathrm{kg} / \mathrm{m}^{2}$ ) and are unlikely to affect any conclusions [7-9]. At all other sites, BMI was calculated from height and weight measured at study enrollment in a clinic setting, with the exception of $140(0.8 \%)$ of the 16,836 WHI subjects whose first available measurements were collected 1 or 3 years after enrollment.

\section{SNP selection and genotyping}

SNPs were selected from GWAS studies published online as of December 31, 2008, based on prior GWAS findings of positive association with BMI or obesity. We analyzed a total of 10 SNPs, after excluding correlated SNPs. Details of the SNP selection process, DNA extraction and genotyping procedures, as well as the association between each of these SNPs and BMI in PAGE have been reported elsewhere [6]. Nine SNPs were analyzed in EA (Table 1), and four SNPs were analyzed in AA (Table 2). We limited our analyses in each group to those SNPs previously associated with BMI in that racial/ ethnic group, either in prior GWAS or in our prior report [10]. We also analyzed rs3751812/FTO in AA because this SNP has been previously associated with BMI in populations with African ancestry, although our previous analyses were underpowered to detect an association [10,11]. We did not analyze rs3751812/FTO in EA because it is strongly correlated with rs9939609/FTO in this population.

\section{Statistical analysis}

All analyses were adjusted for continuous age and stratified by racial/ethnic group. Because it has been described that nicotine has antiestrogenic properties and is metabolized differently in men and women, all analyses were additionally stratified by sex [12]. To evaluate effect modification by current smoking, we estimated the association between each SNP and natural log-transformed BMI (lnBMI) in models using linear regression with robust standard errors (SEs) [13], and including a SNP*smoking (current $=1$ vs. former $/$ never $=0$ ) interaction term. SNP genotype was coded assuming an additive genetic model (i.e., 0 , 1, or 2 copies of the coded allele). We obtained betas specific to current smokers from this model, and to obtain stratum-specific betas for former/never smokers, we re-ran each analysis with a reverse-coded smoking variable (i.e., current $=0$ vs. former $/$ never $=1$ ).

To evaluate the association between each SNP and smoking status, we performed logistic regression using current smoking status as the dependent variable (current $=1$ vs. former/never $=0$ ).

Results (effect sizes and SEs) from each PAGE study were combined with meta-analysis using $R$ [14]. Fixedeffects meta-analysis was used to calculate effect sizes ( $\beta$ for $\operatorname{lnBMI}$ ) and 95\% confidence intervals (CIs) for each SNP. Within strata defined by racial/ethnic group, smoking 
Table 1 Demographic characteristics of PAGE participants, by site, sex, and smoking status Current smokers, females

\begin{tabular}{|c|c|c|c|c|c|c|c|c|c|c|}
\hline & \multicolumn{5}{|c|}{ European Americans } & \multicolumn{5}{|c|}{ African Americans } \\
\hline & total $\mathrm{N}$ & Mean age (SD) & Age range & Mean BMI (SD) & Max BMI & total $\mathrm{N}$ & Mean age (SD) & Age range & Mean BMI (SD) & Max BMI \\
\hline ARIC & 1507 & $53.6(5.6)$ & $44-66$ & $25.3(5.0)$ & 55.2 & 651 & $52.7(5.5)$ & $44-65$ & $28.8(6.1)$ & 52.4 \\
\hline CARDIA & 250 & $25.3(3.4)$ & $18-30$ & $23.7(4.0)$ & 37.8 & 285 & $25.5(3.5)$ & $18-30$ & $26.6(6.1)$ & 45.85 \\
\hline $\mathrm{CHS}$ & 299 & $70.4(4.1)$ & $65-86$ & $25.4(4.6)$ & 44.7 & 68 & $70.9(5.3)$ & $65-86$ & $27.2(5.4)$ & 50.57 \\
\hline EAGLE & 688 & $43.5(17.0)$ & $18-85$ & $26.8(6.2)$ & 53.8 & 500 & $41.4(14.7)$ & $18-90$ & $29.5(7.1)$ & 61.68 \\
\hline MEC & 78 & $56.1(7.6)$ & $45-71$ & $25.8(6.4)$ & 52.6 & 169 & $58.4(8.0)$ & $45-75$ & $28.3(5.8)$ & 48.1 \\
\hline \multirow[t]{2}{*}{ WHI } & 1010 & $64.2(6.6)$ & $50-79$ & $27.4(6.3)$ & 68.8 & 423 & $59.3(6.5)$ & $50-77$ & $30.9(7.0)$ & 63.8 \\
\hline & & & & mean BMlpop (SD) & & & & & mean BMlpop (SD) & \\
\hline Total & 3832 & & & $26.0(5.54)$ & & 2096 & & & $29.0(6.5)$ & \\
\hline
\end{tabular}

Former/never smokers, females

\begin{tabular}{|c|c|c|c|c|c|c|c|c|c|c|}
\hline & \multicolumn{5}{|c|}{ European Americans } & \multicolumn{5}{|c|}{ African Americans } \\
\hline & total N & Mean age (SD) & Age range & Mean BMI (SD) & Max BMl & total N & Mean age (SD) & Age range & Mean BMI (SD) & Max BMl \\
\hline ARIC & 4537 & $54.1(5.7)$ & $44-65$ & $27.1(5.6)$ & 54.7 & 1977 & $53.5(5.8)$ & $44-66$ & $31.5(6.5)$ & 65.9 \\
\hline CARDIA & 716 & $25.7(3.3)$ & $18-30$ & $23.3(4.0)$ & 37.8 & 676 & $24.2(3.9)$ & $18-30$ & $26.6(6.2)$ & 45.85 \\
\hline $\mathrm{CHS}$ & 2214 & $72.6(5.5)$ & $65-100$ & $26.7(4.9)$ & 48.3 & 446 & $73.3(5.7)$ & $65-93$ & $30.1(5.8)$ & 58.79 \\
\hline EAGLE & 3330 & $54.3(18.6)$ & $19-90$ & $27.2(6.2)$ & 64.5 & 1656 & $51.0(14.7)$ & $23-90$ & $30.1(6.8)$ & 51.7 \\
\hline MEC & 579 & $58.9(8.3)$ & $45-76$ & $26.1(5.6)$ & 56.8 & 718 & $60.5(8.9)$ & $45-77$ & $29.2(5.9)$ & 56.2 \\
\hline \multirow[t]{2}{*}{ WHI } & 11865 & $67.3(6.8)$ & $50-79$ & $29.1(6.6)$ & 69.5 & 3538 & $61.7(7.1)$ & $50-79$ & $33.4(7.7)$ & 68.1 \\
\hline & & & & mean BMlpop (SD) & & & & & \multicolumn{2}{|l|}{ mean BMlpop (SD) } \\
\hline Total & \multicolumn{2}{|l|}{23241} & & $28.1(6.1)$ & & \multicolumn{3}{|l|}{9011} & $31.6(7.0)$ & \\
\hline \multicolumn{11}{|c|}{ Current smokers, males } \\
\hline & \multicolumn{5}{|c|}{ European Americans } & \multicolumn{5}{|c|}{ African Americans } \\
\hline & total N & Mean age (SD) & Age range & Mean BMI (SD) & Max BMl & total N & Mean age (SD) & Age range & Mean BMI (SD) & Max BMl \\
\hline ARIC & 1337 & $54.1(5.6)$ & $44-65$ & $26.5(4.0)$ & 56.2 & 622 & $53.7(5.9)$ & $44-66$ & $26.3(4.8)$ & 45.6 \\
\hline CARDIA & 242 & $25.4(3.4)$ & $18-30$ & $24.2(3.4)$ & 34.5 & 208 & $25.1(3.5)$ & $18-30$ & $24.0(3.8)$ & 36.7 \\
\hline $\mathrm{CHS}$ & 184 & $71.3(4.9)$ & $65-90$ & $25.3(3.3)$ & 40.7 & 60 & $70.0(4.7)$ & $65-89$ & $25.9(4.0)$ & 37.65 \\
\hline EAGLE & 859 & $47.1(17.7)$ & $18-90$ & $26.8(5.0)$ & 59.6 & 544 & $44.0(14.9)$ & $18-90$ & $26.2(5.1)$ & 50.41 \\
\hline \multirow[t]{2}{*}{ MEC } & \multirow[t]{2}{*}{68} & \multirow[t]{2}{*}{$59.5(7.8)$} & \multirow[t]{2}{*}{$45-76$} & 26.5 (3.8) & \multirow[t]{2}{*}{37} & \multirow[t]{2}{*}{253} & \multirow[t]{2}{*}{$61.2(7.5)$} & \multirow[t]{2}{*}{$45-76$} & $26.1(4.0)$ & \multirow{2}{*}{45.7} \\
\hline & & & & mean BMlpop (SD) & & & & & mean BMlpop (SD) & \\
\hline Total & \multicolumn{2}{|l|}{2690} & & $26.3(4.3)$ & & \multicolumn{2}{|l|}{1687} & & \multicolumn{2}{|l|}{$25.9(4.7)$} \\
\hline \multicolumn{11}{|c|}{ Former/never smokers, males } \\
\hline & \multicolumn{5}{|c|}{ European Americans } & \multicolumn{5}{|c|}{ African Americans } \\
\hline & total N & Mean age (SD) & Age range & Mean BMI (SD) & Max BMl & total N & Mean age (SD) & Age range & Mean BMI (SD) & Max BMl \\
\hline ARIC & 4089 & $55.0(5.7)$ & $44-66$ & $27.7(4.0)$ & 53.9 & 1008 & $54.0(6.0)$ & $44-66$ & $28.4(4.8)$ & 54.4 \\
\hline CARDIA & 671 & $25.6(3.3)$ & $18-30$ & $24.3(3.2)$ & 34.5 & 487 & $24.0(3.7)$ & $18-30$ & $25.0(4.0)$ & 36.7 \\
\hline $\mathrm{CHS}$ & 1778 & $73.6(5.7)$ & $65-95$ & $26.6(3.7)$ & 46.2 & 245 & $73.3(5.8)$ & $65-93$ & $27.2(4.0)$ & 38.16 \\
\hline EAGLE & 2812 & $62.5(16.9)$ & $18-90$ & $27.66(4.2)$ & 48.4 & 1310 & $53.9(17.1)$ & $19-87$ & $28.6(5.9)$ & 46.4 \\
\hline \multirow[t]{2}{*}{ MEC } & \multirow[t]{2}{*}{603} & \multirow[t]{2}{*}{$61.9(8.1)$} & \multirow[t]{2}{*}{$45-77$} & $26.4(3.8)$ & \multirow[t]{2}{*}{49.6} & 906 & $63.8(7.2)$ & $45-77$ & $27.9(4.2)$ & 51.2 \\
\hline & & & & mean BMlpop (SD) & & & & & mean BMlpop (SD) & \\
\hline Total & 9953 & & & 27.0 (3.9) & & 3956 & & & $27.5(4.5)$ & \\
\hline
\end{tabular}

ARIC Atherosclerosis Risk in Communities Study, CARDIA Coronary Artery Risk in Young Adults, CHS Cardiovascular Health Study, EAGLE Epidemiologic Architecture for Genes Linked to Environment, MEC Multiethnic Cohort, WHI Women's Health Initiative, SD standard deviation, BMI: body mass index; Note: minimum BMI was 18.5 for all sites and ancestry groups.

BMIpop: weighted average of mean BMI reported by each PAGE site. 
Table 2 Complete meta-analysis results in European Americans, effect size expressed in terms of \% difference in mean BMI

\begin{tabular}{|c|c|c|c|c|c|c|c|c|c|c|c|c|c|c|}
\hline \multirow[b]{2}{*}{ Gene } & \multirow[b]{2}{*}{ SNP } & \multirow[b]{2}{*}{ CA } & \multirow[b]{2}{*}{$\operatorname{sex}$} & \multirow[b]{2}{*}{$\begin{array}{l}p \text {-value for } \\
\text { interaction }\end{array}$} & \multicolumn{3}{|l|}{ Current smokers } & \multicolumn{3}{|c|}{ Former/never smokers } & \multicolumn{4}{|c|}{ Combined sex and smoking status* } \\
\hline & & & & & $\begin{array}{c}\text { \% difference in mean BMI } \\
(95 \% \mathrm{Cl})\end{array}$ & $\mathrm{p}$-value & $\mathbf{N}$ & $\begin{array}{c}\text { \% difference in mean BMI } \\
(95 \% \mathrm{Cl})\end{array}$ & p-value & $\mathbf{N}$ & $\begin{array}{c}\text { \% difference in mean BMI } \\
(95 \% \mathrm{Cl})\end{array}$ & p-value & $\mathrm{N}$ & $\mathrm{AF}$ \\
\hline \multirow[t]{2}{*}{ MTCH2 } & rs10838738 & G & $\mathrm{F}$ & 0.40 & $0.6(-0.4-1.51)$ & 0.23 & 2404 & $0.4(-0.2-1.11)$ & 0.20 & 17737 & $0.51(0.22-0.8)$ & $1.0 \mathrm{E}-03$ & 34679 & 0.35 \\
\hline & & & M & 0.24 & $0.3(-0.5-1.11)$ & 0.40 & 1525 & $0.8(0.1-1.41)$ & 0.03 & 4945 & & & & \\
\hline \multirow[t]{2}{*}{ GNPDA2 } & rs10938397 & G & $\mathrm{F}$ & 0.87 & $0.1(-1.39-1.61)$ & 0.88 & 2165 & $0.3(-0.3-1.01)$ & 0.28 & 15961 & $0.29(0.004-0.69)$ & 0.04 & 31346 & 0.43 \\
\hline & & & M & 0.63 & $0.1(-1-1.31)$ & 0.82 & 1398 & $0.5(-0.2-1.21)$ & 0.13 & 3753 & & & & \\
\hline \multirow[t]{2}{*}{ KCTD15 } & rs11084753 & G & $\mathrm{F}$ & 0.42 & $0.8(0.004-1.61)$ & 0.05 & 3447 & $-0.1(-0.7-0.4)$ & 0.60 & 21303 & $0.11(-0.18-0.4)$ & $6.1 \mathrm{E}-01$ & 29411 & 0.67 \\
\hline & & & M & 0.46 & $-0.1(-0.7-0.6)$ & 0.78 & 2321 & $0.2(-0.3-0.7)$ & 0.42 & 7901 & & & & \\
\hline \multirow[t]{2}{*}{ MC4R } & rs12970134 & A & $\mathrm{F}$ & 0.30 & $0.5(-0.6-1.61)$ & 0.38 & 1619 & $0.6(-0.3-1.41)$ & 0.20 & 14992 & $0.8(0.29-1.2)$ & $1.3 \mathrm{E}-03$ & 21987 & 0.26 \\
\hline & & & M & 0.64 & $0.1(-0.9-1.11)$ & 0.85 & 672 & $1.11(-0.3-2.53)$ & 0.12 & 2492 & & & & \\
\hline \multirow[t]{2}{*}{ MC4R } & rs17782313 & C & $\mathrm{F}$ & 0.60 & $0.8(-0.1-1.61)$ & 0.09 & 3449 & $0.7(0.1-1.31)$ & 0.02 & 21334 & $0.22(-0.004-0.51)$ & 0.08 & 35398 & 0.22 \\
\hline & & & M & 0.83 & $0.1(-0.6-0.8)$ & 0.72 & 2326 & $0.6(0.002-1.21)$ & 0.05 & 7930 & & & & \\
\hline \multirow[t]{2}{*}{ NEGR1 } & rs2815752 & T & $\mathrm{F}$ & 0.45 & $0.7(-0.1-1.51)$ & 0.07 & 3393 & $0.2(-0.3-0.7)$ & 0.38 & 20898 & $0.51(0.11-0.8)$ & $9.2 \mathrm{E}-03$ & 28261 & 0.63 \\
\hline & & & M & 0.96 & $0.4(-0.3-1.11)$ & 0.30 & 2272 & $0.1(-0.4-0.6)$ & 0.69 & 7363 & & & & \\
\hline \multirow[t]{2}{*}{ TMEM18 } & rs6548238 & C & $\mathrm{F}$ & 0.15 & $1.11(0.2-2.12)$ & 0.02 & 3424 & $1.21(0.5-1.82)$ & 7.0E-04 & 21261 & $1.02(0.62-1.42)$ & 8.6E-08 & 37061 & 0.83 \\
\hline & & & M & 0.69 & $0.7(-0.2-1.51)$ & 0.12 & 2290 & $0.9(0.2-1.51)$ & 0.01 & 7805 & & & & \\
\hline \multirow[t]{2}{*}{$\mathrm{SH} 2 \mathrm{~B} 1$} & rs7498665 & G & $\mathrm{F}$ & 0.47 & $0.7(-0.2-1.61)$ & 0.11 & 2400 & $0.9(0.3-1.51)$ & $6.0 \mathrm{E}-03$ & 17698 & $0.22(-0.11-0.62)$ & $2.2 \mathrm{E}-01$ & 31383 & 0.38 \\
\hline & & & M & 0.49 & $0.2(-0.6-1.01)$ & 0.67 & 1530 & $0.8(0.1-1.51)$ & 0.02 & 4948 & & & & \\
\hline \multirow[t]{2}{*}{ FTO } & rs9939609 & $A$ & $\mathrm{~F}$ & 0.08 & $1.71(0.9-2.53)$ & 3.5E-05 & 2719 & $0.6(-0.01-1.11)$ & 0.05 & 18221 & $1.31(1.02-1.71)$ & 4.6E-15 & 28286 & 0.40 \\
\hline & & & M & 0.94 & $1.31(0.6-1.92)$ & $2.8 \mathrm{E}-04$ & 1457 & $1.51(1.01-2.12)$ & $6.9 \mathrm{E}-08$ & 5671 & & & & \\
\hline
\end{tabular}


status, and sex, we calculated the population mean BMI $\left(\mathrm{BMI}_{\mathrm{pop}}\right)$ as the weighted average of mean BMIs reported by each PAGE site (Table 3 ). We calculated the mean BMI associated with 1 copy of the risk allele with the following formula: $\mathrm{BMI}_{1 \mathrm{RA}}=\exp \left(\ln \left(\mathrm{BMI}_{\mathrm{pop}}\right)+\beta\right)$. We then subtracted the $\mathrm{BMI}_{\text {pop }}$ from $\mathrm{BMI}_{1 \mathrm{RA}}$ to obtain the difference in mean BMI associated with 1 copy of the risk allele. We evaluated $\mathrm{I}^{2}$ as a measure of heterogeneity [15], to identify any excess variation between the PAGE cohorts. To address potential population stratification, we repeated analyses for studies that had Ancestry Informative Markers (AIMS) (WHI, ARIC, and MEC, representing $>70 \%$ of subjects) including the most significant principal components (PCs) derived from AIMs in each model, and compared the results to unadjusted models.

Finally, as a sensitivity analysis to explore the effect of age, we repeated all analyses excluding subjects enrolled in CARDIA, who tended to be younger than subjects enrolled at the other PAGE sites (Table 3).

\section{Results}

Participant demographics and BMI are detailed in Table 3. Analyses included a total of $39,716 \mathrm{EA}$, and 16,750 AA, with BMI ranging from $18.5-69.5 \mathrm{~kg} / \mathrm{m}^{2}$. Allele frequencies did not differ substantially by smoking status or sex, and thus combined frequencies are presented in all tables. We found no evidence of population stratification, and the sensitivity analysis revealed that excluding subjects enrolled in CARDIA (i.e., younger subjects) did not substantially alter results (data not shown). Thus, we present results unadjusted for PCs, and for all available PAGE subjects (Table 3).

Out of all analyses performed in EA and AAs, none of the SNP*smoking interaction terms were, statistically significant at $\mathrm{p}$-value $\leq 0.05$ (Tables 1 and 2). We observed only two interactions that had p-values $<0.1$ : In AA females, the C vs. A allele of rs6548238/TMEM18 was associated with a $1.82 \%$ difference in mean BMI in former/never smokers, compared to a $0.10 \%$ difference in mean BMI in current smokers ( pinteraction $=0.10$ ). In EA men and women, the difference in BMI associated with the C allele of rs6548238/TMEM18 was very similar in current smokers and former smokers. Rs6548238/ TMEM18 was not associated with smoking status in any of the sex/race groups (data not shown).

Further, we observed that in female EA, the A allele of rs9939609/FTO was almost three-fold more strongly associated with BMI in current smokers $(1.71 \%$ difference in mean BMI) compared with former/never smokers $(0.60 \%$ difference in mean BMI, ( pinteraction $=0.08)$. In EA males, there was no difference in the effect of rs9939609/FTO on BMI by smoking status ( $\mathrm{p}=0.94)$. The A allele of rs9939609/FTO was not associated with current smoking status in either sex (data not shown).
As noted above, rs9939609 was not analyzed in AA due to lack of evidence for an association between this SNP and BMI in African ancestry populations.

\section{Discussion}

In our results, we found little evidence for effect modification by smoking status, although two SNPs (rs6548238/ TMEM18 and rs9939609/FTO) showed weak evidence for interaction that should be followed up in a larger study. There was some evidence that the BMI-increasing effect of the rs6548238/TMEM18 C allele was stronger in AA female former/never smokers. The function of TMEM18 (transmembrane protein 18) is unknown. TMEM18 is highly expressed in neural tissue, and has been hypothesized to play a role in energy homeostasis via neural pathways controlling food intake [16]. Although TMEM18 has not been associated with smoking behavior or nicotine metabolism thus far, smoking may modify the effect of TMEM18 on BMI via energy homeostasis.

The FTO protein may also be involved in neural pathways of energy homeostasis [17]. In our analyses of EA females, the A allele of rs9939609/FTO was more strongly associated with BMI among current smokers compared with former/never smokers, although the analysis was underpowered to detect a statistically significant difference between the two groups. If the effect of this SNP truly differs by smoking status, we still cannot determine if smoking affects the function of the risk allele, or if the risk allele attenuates smoking behavior. The latter hypothesis is supported by a study of 6,877 Polish subjects, in which the A allele of rs $9939609 / F T O$ was associated with older age at smoking initiation and fewer cigarettes smoked per day [18].

Sex-and race/ethnicity-based differences in interaction with smoking could be attributable to differences in smoking behavior, such as cigarette brand choice, and daily vs. occasional "social" smoking [19]. Although we did not have access to such variables, we found no evidence of heterogeneity that would indicate systematic between-group differences.

We did not adjust any analyses to account for multiple testing because we restricted all analyses to SNPs previously known to be associated with BMI. However, these unadjusted results may be prone to increased type 1 error and our results should be replicated in future, larger studies.

\section{Conclusion}

We provide an investigation of the hypothesis that genetic predisposition to obesity may be modified by tobacco use among EA and AA men and women. We observed no strong evidence for SNP"smoking interaction. Despite the relatively large sample size of over 50,000 participants power was limited and future larger studies should 
Table 3 Complete meta-analysis results for African-Americans, effect size expressed in terms of \% difference in mean BMI

\begin{tabular}{|c|c|c|c|c|c|c|c|c|c|c|c|c|c|c|}
\hline \multirow[b]{2}{*}{ Gene } & \multirow[b]{2}{*}{ SNP } & \multirow[b]{2}{*}{ CA } & \multirow[b]{2}{*}{$\operatorname{sex}$} & \multirow[b]{2}{*}{$\begin{array}{l}\text { p-value for } \\
\text { interaction }\end{array}$} & \multicolumn{3}{|l|}{ Current smokers } & \multicolumn{3}{|l|}{ Former/never smokers } & \multicolumn{4}{|c|}{ Combined sex and smoking status* } \\
\hline & & & & & $\begin{array}{l}\text { \% difference in mean } \\
\text { BMI }(95 \% \mathrm{Cl})\end{array}$ & p-value & $\mathbf{N}$ & $\begin{array}{l}\text { \% difference in mean } \\
\text { BMI }(95 \% \mathrm{Cl})\end{array}$ & p-value & $\mathbf{N}$ & $\begin{array}{l}\text { \% difference in mean } \\
\text { BMI }(95 \% \mathrm{Cl})\end{array}$ & p-value & $\mathbf{N}$ & AF \\
\hline \multirow[t]{2}{*}{ GNPDA2 } & rs10938397 & G & $\mathrm{F}$ & 0.60 & $0.5(-0.9-1.92)$ & 0.50 & 1848 & $1.51(0.6-2.43)$ & $9.2 \mathrm{E}-04$ & 7664 & $0.91(0.3-1.41)$ & $1.5 \mathrm{E}-03$ & 14383 & 0.24 \\
\hline & & & M & 0.78 & $1.31(-0.1-2.63)$ & 0.06 & 1455 & $1.51(0.4-2.53)$ & $6.9 \mathrm{E}-03$ & 2831 & & & & \\
\hline \multirow[t]{2}{*}{ MC4R } & rs17782313 & C & $\mathrm{F}$ & 0.53 & $-0.8(-2.08-0.6)$ & 0.27 & 1758 & $0.6(-0.2-1.51)$ & 0.15 & 7365 & $0.6(0.03-1.11)$ & $4.0 \mathrm{E}-02$ & 13698 & 0.29 \\
\hline & & & M & 0.31 & $-0.1(-1.29-1.21)$ & 0.93 & 1339 & $1.21(0.2-2.22)$ & 0.02 & 2682 & & & & \\
\hline \multirow[t]{2}{*}{ FTO } & rs3751812 & $\mathrm{T}$ & $\mathrm{F}$ & 0.34 & $-0.1(-2.76-2.63)$ & 0.94 & 774 & $0.4(-1.09-1.92)$ & 0.61 & 4505 & $0.4(-1.11-2.01)$ & 0.60 & 4549 & 0.12 \\
\hline & & & M & 0.61 & $2.53(0.2-4.92)$ & $3.0 \mathrm{E}-02$ & 329 & $1.51(-0.3-3.25)$ & 0.11 & 565 & & & & \\
\hline \multirow[t]{2}{*}{ TMEM18 } & rs6548238 & C & $\mathrm{F}$ & 0.10 & $0.1(-1.78-2.02)$ & 0.95 & 1876 & $1.82(0.7-2.94)$ & 0.002 & 7707 & $1.31(0.6-2.01)$ & $2.4 \mathrm{E}-04$ & 14492 & 0.88 \\
\hline & & & M & 0.64 & $2.43(0.7-4.08)$ & 0.01 & 1463 & $0.9(-0.4-2.22)$ & 0.18 & 2855 & & & & \\
\hline
\end{tabular}

CA Coded allele, $M$ male, $F$ female, $C l$ confidence interval, $A F$ coded allele frequency. 
investigate the potential sex-specific effects of smoking on each variant's association with energy balance.

\section{Competing interests}

The authors declare that they have no competing interests.

\section{Authors' contributions}

MDF, KEN, DCC, MDG, JHF, SL, MG, CSC, LHK, TCM, CPH, BEH, MA, PM, NSB KRM, MDR, RLP, LNK, JEM, JP, LAH, NF, LRW, CAH, LLM, UP participated in the design of the study. DF, UL, PB JH, RG RRR, JP performed the statistical analysis. MDF and UP drafted the manuscript. All authors read and commented on the manuscript and approved the final manuscript.

\section{Acknowledgements}

The Population Architecture Using Genomics and Epidemiology (PAGE) program is funded by the National Human Genome Research Institute (NHGRI), supported by U01HG004803 (CALiCo), U01HG004798 (EAGLE), U01HG004802 (MEC), U01HG004790 (WHI), and U01HG004801 (Coordinating (enter), and their respective NHGRI ARRA supplements. The contents of this paper are solely the responsibility of the authors and do not necessarily represent the official views of the $\mathrm{NIH}$. The complete list of PAGE members can be found at http://www.pagestudy.org.

The data and materials included in this report result from a collaboration between the following studies:

The "Epidemiologic Architecture for Genes Linked to Environment (EAGLE)" is funded through the NHGRI PAGE program (U01HG004798-01 and its NHGRI ARRA supplement). Genotyping services for select NHANES III SNPS presented here were also provided by the Johns Hopkins University under federal contract number (N01-HV-48195) from NHLBI. The study participants derive from the National Health and Nutrition Examination Surveys (NHANES), and these studies are supported by the Centers for Disease Control and Prevention. The findings and conclusions in this report are those of the authors and do not necessarily represent the views of the Centers for Disease Control and Prevention.

The Multiethnic Cohort study (MEC) characterization of epidemiological architecture is funded through the NHGRI PAGE program (U01HG004802 and its NHGRI ARRA supplement). The MEC study is funded through the National Cancer Institute (R37CA54281, R01 CA63, P01CA33619, U01CA136792, and U01CA98758).

Funding support for the "Epidemiology of putative genetic variants: The Women's Health Initiative" study is provided through the NHGRI PAGE program (U01HG004790 and its NHGRI ARRA supplement). The WHI program is funded by the National Heart, Lung, and Blood Institute; $\mathrm{NIH}$; and U.S. Department of Health and Human Services through contracts N01WH22110, 24152, 32100-2, 32105-6, 32108-9, 32111-13, 32115, 32118-32119, 32122, $42107-26,42129-32$, and 44221. The authors thank the WHI investigators and staff for their dedication, and the study participants for making the program possible. A full listing of WHI investigators can be found at: http:// www.whiscience.org/publications/ WHI_investigators_shortlist.pdf. Funding support for the Genetic Epidemiology of Causal Variants Across the Life Course (CALiCo) program was provided through the NHGRI PAGE program (U01HG004803 and its NHGRI ARRA supplement). The following studies contributed to this manuscript and are funded by the following agencies: The Atherosclerosis Risk in Communities (ARIC) Study is carried out as a collaborative study supported by National Heart, Lung, and Blood Institute contracts N01-HC-55015, N01-HC-55016, N01-HC-55018, N01-HC55019, N01-HC-55020, N01-HC-55021, N01-HC-55022. The Coronary Artery Risk Development in Young Adults (CARDIA) study is supported by the following National Institutes of Health, National Heart, Lung and Blood Institute contracts: N01-HC-95095; N01-HC-48047; NO1-HC-48048; NO1-HC48049; N01-HC-48050; N01-HC-45134; N01-HC-05187; and N01-HC-45205. The Cardiovascular Health Study (CHS) is supported by contracts HHSN268201200036C, N01-HC-85239, N01-HC-85079 through N01-HC-85086, N01-HC-35129, N01 HC-15103, N01 HC-55222, N01-HC-75150, N01-HC-45133, and grant HL080295 from the National Heart, Lung, and Blood Institute (NHLBI), with additional contribution from the National Institute of Neurological Disorders and Stroke (NINDS). Additional support was provided through AG-023629, AG-15928, AG-20098, and AG-027058 from the National Institute on Aging (NIA). The Strong Heart Study (SHS) is supported by NHLBI grants U01 HL65520, U01 HL41642, U01 HL41652, U01 HL41654, and U01
HL65521. The opinions expressed in this paper are those of the author(s) and do not necessarily reflect the views of the Indian Health Service. Assistance with phenotype harmonization, SNP selection and annotation, data cleaning, data management, integration and dissemination, and general study coordination was provided by the PAGE Coordinating Center (U01HG004801-01 and its NHGRI ARRA supplement). The National Institutes of Mental Health also contributes to the support for the Coordinating Center.

\section{Author details}

'Division of Public Health Sciences, Fred Hutchinson Cancer Research Center, 1100 Fairview Ave N, M4-B402, PO Box 19024, Seattle, WA 98109-1024, USA. ${ }^{2}$ Carolina Center for Genome Sciences, School of Public Health, University of North Carolina, Chapel Hill, NC 27514, USA. ${ }^{3}$ Department of Epidemiology, School of Public Health, University of North Carolina at Chapel Hill, Chapel Hill, NC 27514, USA. ${ }^{4}$ Epidemiology Program, University of Hawaii Cancer Center, Honolulu, HI 96813, USA. ${ }^{5}$ Department of Biostatistics, University of Washington, Seattle, USA. ${ }^{6}$ Center for Human Genetics Research, Vanderbilt University Medical Center, Nashville, TN 37203, USA. ${ }^{7}$ Department of Laboratory Medicine and Pathology, Medical School, University of Minnesota, Minneapolis, MN 55455, USA. ${ }^{8}$ Vanderbilt Epidemiology Center, Vanderbilt University Medical Center, Nashville, TN 37203, USA. ${ }^{9}$ Department of Medicine, University of Pittsburgh, Pittsburgh, PA, USA. ${ }^{10}$ Department of Statistics \& Biostatistics, Rutgers University, Piscataway, NJ 08854, USA. ${ }^{11}$ Division of Epidemiology and Community Health, University of Minnesota School of Public Health, Minneapolis, MN, USA. ${ }^{12}$ Department of Preventive Medicine, Keck School of Medicine / Norris Comprehensive Cancer Center, University of Southern California, Los Angeles, CA, USA. ${ }^{13}$ Brigham and Women's Hospital, Harvard Medical School, Boston, MA 02115, USA. ${ }^{14}$ Office of Population Genomics, National Human Genome Research Institute, National Institutes of Health, Bethesda, MD, USA.

Received: 8 August 2012 Accepted: 3 January 2013

Published: 11 January 2013

\section{References}

1. Loos RJ: Recent progress in the genetics of common obesity. Br J Clin Pharmacol 2009, 68:811-829.

2. Chiolero A, Faeh D, Paccaud F, Cornuz J: Consequences of smoking for body weight, body fat distribution, and insulin resistance. Am J Clin Nutr 2008, 87:801-809.

3. Mineur YS, Abizaid A, Rao Y, Salas R, DiLeone RJ, Gündisch D, Diano S, De Biasi M, Horvath TL, Gao XB, Picciotto MR: Nicotine decreases food intake through activation of POMC neurons. Science 2011, 332:1330-1332.

4. Nicklas BJ, Tomoyasu N, Muir J, Goldberg AP: Effects of cigarette smoking and its cessation on body weight and plasma leptin levels. Metabolism 1999, 48:804-808.

5. Matise TC, Ambite JL, Buyske S, Carlson CS, Cole SA, Crawford DC, Haiman CA, Heiss G, Kooperberg C, Marchand LL, Manolio TA, North KE, Peters U, Ritchie MD, Hindorff $L A$, Haines JL, PAGE Study: The next PAGE in understanding complex traits: design for the analysis of Population Architecture Using Genetics and Epidemiology (PAGE) study. Am J Epidemiol 2011, 174:849-859.

6. Fesinmeyer MD, North KE, Ritchie MD, Lim U, Franceschini N, Wilkens LR, Gross MD, Bůžková P, Glenn K, Quibrera PM, Fernández-Rhodes L, Li Q, Fowke JH, Li R, Carlson CS, Prentice RL, Kuller LH, Manson JE, Matise TC, Cole SA, Chen CT, Howard BV, Kolonel LN, Henderson BE, Monroe KR, Crawford DC, Hindorff LA, Buyske S, Haiman CA, Le Marchand L, Peters U: Genetic risk factors for body mass index and obesity in an ethnically diverse population: results from the PAGE study. Obesity (Silver Spring) 2012, doi:10.1038/oby.2012.158. Epub ahead of print.

7. Gillum RF, Sempos CT: Ethnic variation in validity of classification of overweight and obesity using self-reported weight and height in American women and men: the Third National Health and Nutrition Examination Survey. Nutr J 2005, 4:27.

8. Gorber SC, Tremblay MS: The bias in self-reported obesity from 1976 to 2005: a Canada-US comparison. Obesity (Silver Spring) 2010, 18:354-361.

9. Bes-Rastrollo M, Sabaté J, Jaceldo-Siegl K, Fraser GE: Validation of selfreported anthropometrics in the Adventist Health Study 2. BMC Public Health 2011, 11:213. 
10. Hassanein MT, Lyon HN, Nguyen TT, Akylbekova EL, Waters K, Lettre G, Tayo B, Forrester T, Sarpong DF, Stram DO, Butler JL, Wilks R, Liu J, Le Marchand L, Kolonel LN, Zhu X, Henderson B, Cooper R, McKenzie C, Taylor HA Jr, Haiman CA, Hirschhorn JN: Fine mapping of the association with obesity at the FTO locus in African-derived populations. Hum Mol Genet 2010, 19:2907-2916.

11. Grant SF, Li M, Bradfield JP, Kim CE, Annaiah K, Santa E, Glessner JT, Casalunovo T, Frackelton EC, Otieno FG, Shaner JL, Smith RM, Imielinski M, Eckert AW, Chiavacci RM, Berkowitz RI, Hakonarson H: Association analysis of the FTO gene with obesity in children of Caucasian and African ancestry reveals a common tagging SNP. PLoS One 2008, 3:e1746.

12. Pauly JR: Gender differences in tobacco smoking dynamics and the neuropharmalogical actions of nicotine. Front Biosci 2008, 13:505-16

13. Kleinbaum D, Kupper L, Muller K: Applied Regression Analysis and Other Multivariable Models. 2nd edition. Belmont, CA: Duxbury Press; 1988.

14. R Development Core Team: R: A Lanquage and Environment for Statistical Computing. Vienna, Austria: R Foundation for Statistical Computing; 2010.

15. Higgins JP, Thompson SG, Deeks JJ, Altman DG: Measuring inconsistency in meta-analyses. BMJ 2003, 327:557-560.

16. Almén MS, Jacobsson JA, Shaik JH, Olszewski PK, Cedernaes J, Alsiö J, Sreedharan S, Levine AS, Fredriksson R, Marcus C, Schiöth HB: The obesity gene, TMEM18, is of ancient origin, found in majority of neuronal cells in all major brain regions and associated with obesity in severely obese children. BMC Med Genet 2010, 11:58.

17. Fawcett KA, Barroso I: The genetics of obesity: FTO leads the way. Trends Genet 2010, 26:266-274.

18. Sobczyk-Kopciol A, Broda G, Wojnar M, Kurjata P, Jakubczyk A, Klimkiewicz A, Ploski R: Inverse association of the obesity predisposing FTO rs9939609 genotype with alcohol consumption and risk for alcohol dependence. Addiction 2011, 106:739-748.

19. Levy DE, Biener L, Rigotti NA: The natural history of light smokers: a population-based cohort study. Nicotine Tob Res 2009, 11:156-163.

doi:10.1186/1471-2350-14-6

Cite this article as: Fesinmeyer et al:. Effects of smoking on the genetic risk of obesity: the population architecture using genomics and epidemiology study. BMC Medical Genetics 2013 14:6.

\section{Submit your next manuscript to BioMed Central and take full advantage of:}

- Convenient online submission

- Thorough peer review

- No space constraints or color figure charges

- Immediate publication on acceptance

- Inclusion in PubMed, CAS, Scopus and Google Scholar

- Research which is freely available for redistribution 